\title{
Analisa Potensi Pengembangan Energi Alternative Berbasis Limbah Kelapa Di Kabupaten Indragiri Hilir
}

\author{
Khairul Ihwan, Roberta Zulfhi Surya \\ Program Studi Teknik Industri, Universitas Islam Indragiri \\ JIn. Provinsi Parit 1 Tembilahan - Indragiri Hilir-Riau \\ Email : ihwanp5@hgmail.com,robertazulfhi@yahoo.co.id
}

\begin{abstract}
Indragiri Hilir Regency has the largest coconut plantation in Indonesia with coconut production reaching 390,924.28 tons per year and land area of 295,380.24 hectares (BPS Inhil Regency, 2012). According to Palunkun in Prananta (2004) the composition of coconuts consists of coir 35\%, coconut shell $12 \%$, fruit flesh $28 \%$ coconut water 25\%. So the number of coir and coconut shell that has been burned is $47 \%$ of the production of coconut grains. So that coir and shell waste is 643,070,441 tons of waste. Based on research that has been done in the area of extranmigration in Pelangiran sub-district and Belengkong bay sub-district, the potential of coconut waste in the form of coconut fiber is 7,406,000 kg. if the coconut plantations are harvested at the same time. The duration of the harvest for 2.5 to 3 months each time. So that the potential of coconut waste (coconut husk) is $82.288 .89 \mathrm{~kg} /$ day multiply the calorie value of coconut fiber at $4.004 .8 \mathrm{k}$.cal is $329,546,982.40 \mathrm{~K}$. Kal / kg. if converted into electrical energy with a conversion factor of every tonne of calories is 1.1628x 10-3 MWh (Energy Outlook Statistics, University of Indonesia, 2000) then the potential electrical energy from waste to be produced is 329,546.98 Ton K.Kal X 1, $1628 \times 10-3 \mathrm{MWh} .=0.383263 \mathrm{Kwh}$.
\end{abstract}

Keywords: Alternative Energy, coconut waste, biomass

\section{Abstrak}

Kabupaten Indragiri Hilir (Inhil) memiliki perkebunan kelapa terluas di Indonesia dengan produksi kelapa dalam mencapai 390.924,28 ton pertahun dan luas lahan 295.380,24 Ha.(BPS Kab. Inhil, 2012). Menurut Palunkun dalam Prananta (2004) komposisi buah kelapa terdiri sabut 35\%, tempurung 12\%, Daging buah 28\% air kelapa 25\%. Maka jumlah sabut dan tempurung kelapa yang selama ini di bakar adalah 47\% dari produksi kelapa butir. Sehingga limbah sabut dan tempurung adalah 643.070.441 ton limbah. Berdasarkan penelitan yang telah dilakukan di kawasan daerah extranmigrasi yang berada di kecamtan pelangiran dan kecamatan teluk Belengkong potensi limbah kelapa yang berupa sabut kelapa sebesar 7.406.000,- kg. jika perkebunan kelapa itu di panen dalam waktu bersamaan. Adapun durasi waktu panen selama 2,5 s/d 3 bulan setiap kali panen. Sehingga potensi limbah kelapa (sabut kelapa) sebesar $82,288.89 \mathrm{~kg} / \mathrm{hari}$ di kalikan nilai kalor sabut kelapa sebesar 4.004, $8 \mathrm{k}$.kal adalah 329,546,982.40 K.Kal/kg. jika dikonversikan menjadi energi listrik dengan faktor konversi setiap ton kalori adalah 1,1628x 10-3 MWh (Energi Outlook Statistics, University of Indonesia, 2000) maka potesi energi listrik dari limbah kekapa yang akan dihasilkan adalah 329.546,98 Ton K.Kal X 1,1628 x 10-3 MWh. $=0.383263 \mathrm{Kwh}$. 


\section{PENDAhuluan}

Kabupaten Indragiri Hilir (Inhil) memiliki perkebunan kelapa terluas di Indonesia dengan produksi kelapa dalam mencapai $390.924,28$ ton pertahun dan luas lahan 295.380,24 Ha.(BPS Kab. Inhil, 2012) Pada umumnya masyarakat mengolah kelapa menjadi kopra. Dengan tingkat produktifitas kelapa di kabupaten indragiri hilir $390.924,28$ ton setara kopra atau 1.368.234.980 ton skala kelapa butir dengan asumsi perbutir memiliki berat rata-rata $1 \mathrm{~kg}$. Menurut Palunkun dalam Prananta (2004) komposisi buah kelapa terdiri sabut $35 \%$, tempurung $12 \%$, Daging buah $28 \%$ air kelapa $25 \%$. Maka jumlah sabut dan tempurung kelapa yang selama ini di bakar adalah $47 \%$ dari produksi kelapa butir. Sehingga limbah sabut dan tempurung adalah 643.070.441 ton limbah.

Selama ini limbah kelapa yang sudah dimanfaatkan secara komersil adalah tempurung kelapa. Tempurung kelapa di dunakan masyarakat untuk membuat arang dengan cara pembakaran secara manual. Sementara itu sabut dan air kelapa belum dimanfaatkan secara komersil, untuk menghindarai tumpukan dan hewan berbahaya yang bersarang di tumpukan sabut biasanya masyarakat membakar sabut tersebut. Sementara untuk air kelapa masyarakat membuang begitu saja. Karena tidak adanya permintaan untukair kelapa. Berdasarkan permasalhan diatas penulisi akan mencoba melakukan "analisa potensi pengembangan energi alternative berbasis limbah kelapa di kabupaten Indragiri" penelitian ini dilakukan pada kawasan extrans perkebunan kelapa hibrida, PT GHS 1 di kecamatan Pelangiran dan Teluk Belengkong kabupaten Indragiri Hilir.

Berdasarkan survey awal dan wawancara dengan pejabat desa kawasan ini memiliki perkebunan kelapa yang sangat luas dengan peroduksi sabut sekitar 50 ton perhari. Dan transportasi meggunakan armada air dengan system parit atau kanal yang terhubung dari satu tempat ke tempat lain sehingga sangat efesien untuk mengangkut dalam jumlah besar seperti sabut kelapa.Jika hasil penelitian ini positif maka sangat layak jika di kawasan tersebut di bangun pembangkit listrik berbasis limbah sabut untuk menerangain 2.500 kepala keluarga.

\section{METODELOGI PENELITIAN}

Metode penelitian yang digunakan daalam penelitian ini menggunakan metode studi literature dan studi lapangan. Metode studi literatur yang digunkan berupa artikel ilmiah, jurnal, media online dan beberapa sumber literature lain yang relevan. Sedaangkan studi lapangan dilakukan untuk menghitung potensi pengembangan energi alternatif berbasis limbah kelapa dikabupaten Indragiri Hilir. penelitian ini dilakukan pada kawasan extrans perkebunan kelapa hibrida, PT GHS 1 di kecamatan Pelangiran dan Teluk Belengkong kabupaten Indragiri Hilir

Pengumpulan data limbah kelapa berupa sabut kelapa dilakukan dengan cara melakukan studi literatur yang digunkan berupa artikel ilmiah, jurnal, media online dan beberapa sumber literature lain yang relevan. Sedaangkan studi lapangan dilakukan untuk menghitung potensi pengembangan energi alternatif berbasis limbah kelapa dikabupaten Indragiri Hilir penelitian ini dilakukan pada kawasan extrans perkebunan kelapa hibrida, PT GHS 1 di kecamatan Pelangiran dan Teluk Belengkong kabupaten Indragiri Hilir. Data yang dihasilkan dari penelitian ini adalah jumla potensi limbah kelapa 
yaitu sabut kelapa, di ketahui bahwa setiap ton buah kelapa terdapat $360 \mathrm{~kg}$ serabut kelapa dan 165 kg cangkang kelapa, Lembaga Penelitian Hasil Hutan, (1978). Dari potensi limbah tersebut di konversikan menjadi potensi energi alternatif berupa energi listrik (kwh) dengan cara menghitung nilai kalor dari sebut kelapa terlebih dahulu.

\section{Penghitungan Nilai Kalor}

Kalor didefinisikan sebagai energi panas yang dimiliki oleh suatu zat. Kalor jenis (c) adalah banyaknya kalor (Q) yang dibutuhkan untuk menaikkan suhu (T) satu satuan massa (m) benda sebesar satu derajat. (Perrys, 2007).

$\mathrm{Q}=\mathrm{m} . \mathrm{c} .(\mathrm{t} 2-\mathrm{t} 1) \ldots$

(Perrys, 2007)

Dimana :

$\mathrm{Q}=$ kalor yang dibutuhkan $(\mathrm{J})$

$\mathrm{m}=$ massa benda $(\mathrm{kg})$

$\mathrm{c}=$ kalor jenis $(\mathrm{J} / \mathrm{kgC})$

(t2-t1) adalah perubahan suhu (C)

Kalor jenis biomassa digunakan untuk menghitung energi kalor total. Daftar kalor jenis biomassa ada ditabel berikut :

Tabel 1. Nilai kalor limbah biomassa

\begin{tabular}{|c|c|}
\hline Limbah Biomassa & Kalor Jenis \\
\hline $\begin{array}{l}\text { Padi } \\
\text { 1. Sekam } \\
\text { 2. Jerami } \\
\text { 3. Merang }\end{array}$ & $\begin{array}{l}\text { 3.052,9 Ton } \mathrm{Kal} / \text { Ton } \\
\text { 2.914,5 Ton } \mathrm{Kal} / \text { Ton } \\
\text { 3.205,4 Ton } \mathrm{Kal} / \text { Ton }\end{array}$ \\
\hline $\begin{array}{l}\text { Jagung } \\
\text { 1. Bonggol } \\
\text { 2. Batang-daun } \\
\text { 3. Kelobot }\end{array}$ & $\begin{array}{l}3.523,9 \text { Ton } \mathrm{Kal} / \text { Ton } \\
\text { 3.674,6 Ton } \mathrm{Kal} / \text { Ton } \\
\text { 3.620,6 Ton } \mathrm{Kal} / \text { Ton }\end{array}$ \\
\hline $\begin{array}{l}\text { Singkong } \\
\text { 1. Batang }\end{array}$ & 3.894,5 Ton $\mathrm{Kal} / \mathrm{Ton}$ \\
\hline $\begin{array}{l}\text { Kelapa Sawit } \\
\text { 1. Serabut } \\
\text { 2. Tempurung } \\
\text { 3. Tandan }\end{array}$ & $\begin{array}{l}11,40 \text { Ton } \mathrm{Kal} / \text { Ton } \\
15,21 \text { Ton } \mathrm{Kal} / \text { Ton } \\
3.700(\mathrm{k} . \mathrm{kal} / \mathrm{kg})\end{array}$ \\
\hline $\begin{array}{l}\text { Kelapa } \\
\text { 1. Serabut } \\
\text { 2. Tempurung }\end{array}$ & 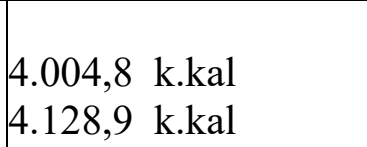 \\
\hline $\begin{array}{l}\text { Hasil Hutan } \\
\text { 1. Kayu }\end{array}$ & 3.992,6 Ton $\mathrm{Kal} / \mathrm{Ton}$ \\
\hline
\end{tabular}

(Sumber : Lembaga Penelitian Hasil Hutan, 1978)
Jika kapasitas produksi energi panas yang dihasilkan tersebut dikonversikan menjadi energi alternatif berupa listrikdengan faktor konversi setiap ton kalori adalah 1,1628x 10-3 MWh (Energi Outlook Statistics, University of Indonesia,2000), maka dapatdi perkirakan berapa potensi energi listrik yang di dapat dari limbah kelapa yaitu sabut kelapa di daerah ekstran GHS 1 yang berada di dua kecamatan yaitu kecamatan pelangiran dan kecamatan teluk belengkong.

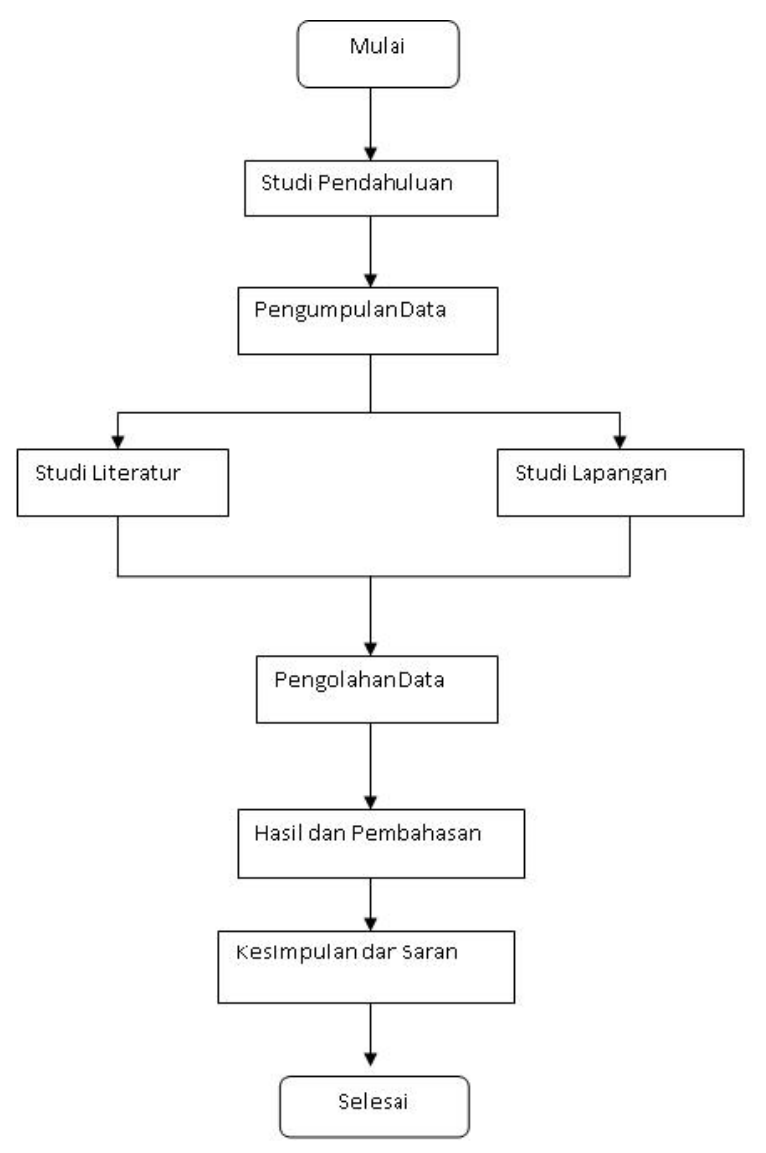

(Diagram Penelitian)

\section{HASIL DAN PEMBAHASAN}

Berdasarkan hasil penelitian yang telah dilakuakan, dapat di jelaskan beberapa point dalam penelitian ini yaitu:

1. Lokasi Penelitian : Kawasan extrans perkebunan kelapa hibrida, PT GHS 1 di kecamatan Pelangiran dan Teluk Belengkong kabupaten Indragiri Hilir. 

2. Objek Penelitian : Limbah Kelapa Hibrida (sabut kelapa hibrida)
3. Data produksi kelapa, potensi limbah kelapa sebagai berikut:

Tabel Produksi kelapa, potensi limbah kelapa

\begin{tabular}{|c|c|c|c|c|c|c|c|c|}
\hline \multirow{2}{*}{ No } & \multirow{2}{*}{\multicolumn{2}{|c|}{ Kawasan }} & \multirow{2}{*}{ Kecamtan } & \multicolumn{2}{|c|}{$\begin{array}{l}\text { Luas Perkebunan } \\
\text { Kelapa Hibrida }\end{array}$} & \multirow{2}{*}{$\begin{array}{l}\text { Rata- rata } \\
\text { Produktifitas } \\
(2500 / h)\end{array}$} & \multicolumn{2}{|c|}{$\begin{array}{l}\text { Potensi Limbah sabut kelapa ( } \\
\text { 35\% dari berat kelapa) }\end{array}$} \\
\hline & & & & $\begin{array}{l}\text { Jumlah } \\
\text { kavling }\end{array}$ & $\begin{array}{l}\text { Hektar } \\
(2 \text { h/Kav })\end{array}$ & & Berat kelapa $(0.8)$ & Berat Sabut \\
\hline 1 & SP & 1 & $\begin{array}{l}\text { Teluk } \\
\text { Bengkong }\end{array}$ & 500 & 1,000 & $2,500,000$ & $2,000,000$ & 700,000 \\
\hline 2 & SP & 2 & Pelangiran & 500 & 1,000 & $2,500,000$ & $2,000,000$ & 700,000 \\
\hline 3 & SP & 3 & $\begin{array}{l}\text { Teluk } \\
\text { Bengkong }\end{array}$ & 300 & 600 & $1,500,000$ & $1,200,000$ & 420,000 \\
\hline 4 & SP & 4 & Pelangiran & 170 & 340 & 850,000 & 680,000 & 238,000 \\
\hline 5 & SP & 5 & $\begin{array}{l}\text { Teluk } \\
\text { Bengkong }\end{array}$ & 500 & 1,000 & $2,500,000$ & $2,000,000$ & 700,000 \\
\hline 6 & SP & 6 & Pelangiran & 350 & 700 & $1,750,000$ & $1,400,000$ & 490,000 \\
\hline 7 & SP & 7 & $\begin{array}{l}\text { Teluk } \\
\text { Bengkong }\end{array}$ & 500 & 1,000 & $2,500,000$ & $2,000,000$ & 700,000 \\
\hline 8 & $\mathrm{SP}$ & 8 & Pelangiran & 500 & 1,000 & $2,500,000$ & $2,000,000$ & 700,000 \\
\hline 9 & SP & 10 & Pelangiran & 300 & 600 & $1,500,000$ & $1,200,000$ & 420,000 \\
\hline 10 & $\mathrm{SP}$ & 11 & Pelangiran & 500 & 1,000 & $2,500,000$ & $2,000,000$ & 700,000 \\
\hline 11 & $\mathrm{SP}$ & 12 & Pelangiran & 500 & 1,000 & $2,500,000$ & $2,000,000$ & 700,000 \\
\hline 12 & $\mathrm{SP}$ & 13 & $\begin{array}{l}\text { Teluk } \\
\text { Bengkong }\end{array}$ & 170 & 340 & 850,000 & 680,000 & 238,000 \\
\hline 13 & $\mathrm{SP}$ & 14 & Pelangiran & 500 & 1,000 & $2,500,000$ & $2,000,000$ & 700,000 \\
\hline \multicolumn{4}{|c|}{ Jumalah } & 5,290 & 10,580 & $26,450,000$ & $21,160,000$ & $7,406,000$ \\
\hline
\end{tabular}

Sumber data : Observasi dan wawancara dengan masyarakat dan aparat pemerintah desa.

Dari tabel di atas dapat di jelaskan bahawa potensi limbah kelapa berupa sabut kelapa di daerah penelitian dapat di perkirakan sebesar sekitar $7,406,000 \mathrm{~kg}$ (7,406 ton) setiap kali panen. Di ketahuai durasi panen kelapa selama 3 bulan atau 90 hari. Jika di konversikan potensi limbah setiap harinya sebesar $82,288 \mathrm{~kg}$ atau 82 ton per hari.

\section{PEMBAHASAN \\ Pengolahan Data}

Untuk mengetahui berapa besar potensi energy alternatif yang dihasilkan dari limbah kelapa yang berada di lokasi penelitian yaitu kawasan ekstran PT GHS I dapat di lakukan dengan cara sebagai berikut:

\section{Menentukan nilai kalor}

Berdasarkan penelitian yang telah di lakukan Lembaga Penelitian Hasil Hutan, (1978) nilai kalor dari limbah kelapa dalam penelitian ini sabut kelapa sebesar 4.004,8 $\quad$ k.kal./kg sedangkan potensi limbah sabut kelapa perhari sebesar 82 ton dengan potensi kalori sebesar $329.546 .982,4$ k.kal.

\section{Menentukan Potensi Energy Alternatif}

Potensi nilai kalor yang di peroleh dari 82 ton sabut kelapa dengan nilai kalor sebesar 329.546.982,4 k.kal bila di konversikan ke energi listrik dengan menggunkan aplikasi Convert Live (https://convertlive.com/id/u/mengkonversi/kalor i-per-jam/ke/watt )di peroleh 383.263,14 watt.

Dari pengolahan data dan pembahasan yang telah dilakukan dapat di terangkan bahwa potensi limbah kelapa berupa sabut kelapa di sebesar 82 ton perhari dengan nilai kalor 329.546.982,4 k.kal dan bila di konversikan ke dalam energi listrik dengan menggunkan aplikasi Convert Live (https://convertlive.com/id/u/mengkonversi/kalor i-per-jam/ke/watt )di peroleh 383.263,14 watt. Dimana lokasi penelitian ini berada di kawasan Ekstran PT GHS I yang berada di kecamatan 
pelangiran dan teluk belengkong yang terdiri dari 13 SP (satuan Perumahan) atau 13 Desa.

\section{KESIMPULAN}

Berdasarkan hasil penelitian ini dapat di simpulkan bahwa limabah kelapa berupa sabut kelapa yang terdapat di kawasan exstransmigrasi yang berada di dua kecamatan yaitu kecamatan pelangiran dan kecamatan teluk belengkong dapat di simpulkan sebagai berikut:

1. sampai saat ini belum di manfaatkan dan hanya di bakar sebagai upaya pengurangan penumpukan limbah.

2. Potensi limbah kelapa di perkirakan sebesar sekitar 7,406,000 kg (7,406 ton) setiap kali panen. Di ketahuai durasi panen kelapa selama 3 bulan atau 90 hari.

3. Jika di konversikan potensi limbah setiap harinya sebesar $82,288 \mathrm{~kg}$ atau 82 ton per hari Potensi nilai kalor yang di peroleh dari 82 ton sabut kelapa dengan nilai kalor sebesar 329.546.982,4 k.kal bila di konversikan ke energi listrik dengan menggunkan aplikasi Convert

Live (https://convertlive.com/id/u/mengkonversi/ka lori-per-jam/ke/watt )di peroleh 383.263,14 watt.

\section{DAFTAR PUSTAKA}

Anonymous, "Net Heating Value dari Limbah Pertanian, Kayu Bakar, Arang Dibandingkan dengan Batubara dan Minyak Tanah", Lembaga Penelitian Hasil Hutan, Bogor, Indonesia, 1978

Bono. P, Marlina.P, Silvy . R, Syaiful .N , 2013, "Peta Potensi Limbah Biomassa Pertanian Dan Kehutanan Sebagai Basis Data Pengembangan Energi Terbarukan",Jurnal : Ketenagalistrikan Dan Energi Terbarukan Vol. 12 No. 2 Desember 2013 : 123 - 130, ISSN 1978-2365
Energi Outlook Statistics, University of Indonesia, 2000

Krisnawati $\mathrm{H}$, Adinugroho $\mathrm{CW}$, Imanudin $\mathrm{R}$. 2013. Pedoman Penggunaan Model Alometrik untuk Pendugaan Biomassa dan Stok Karbon di Indonesia. Bogor (ID): Pusat Penelitian dan Pengembangan Konservasi dan Rehabilitasi, Badan Penelitian dan Pengembangan Kehutanan - Kementerian Kehutanan.

Malau S.M. 2015. Analisis Biomassa dan Cadangan Karbon Bambu Tali (Gigantochloa pruriens K.) di Hutan Tanaman Rakyat Desa Sirpang Sigodang Kecamatan Panei, Kabupaten Simalungun. Universitas Sumatera Utara. Medan.

Sutaryo, D. 2009. Penghitungan Biomassa. Sebuah Pengantar Untuk Studi Karbon danPerdagangan Karbon. Wetlands International Indonesia Programme. Bogor.

Perry, R.H. and Green, D.W "Perry's Chemical Engineers' Handbook" , McGraw-Hill, October 2007 (8th Edition), ISBN 0-07142294-3

Sudaryanto T, I W. Rusastra, dan P. Simatupang, 1998 , "Strategi Dan Kebijakan Pembangunan Ekonomi Pedesaan Berbasis Agribisnis “, Prosiding Seminar dan Ekspose Hasil Penelitian/Pengkajian BPTP Jawa Timur ,ISBN: 979-8094-86-7

Tim Penyusun PS, 1996, Kelapa sawit, Usaha Budidaya Pemanfaatan Hasil dan Aspek Pemasaran nya,cetakan ke V, Penerbit PT Penebar Swadaya, anggota IKAPI, Jl. Gunung Sahari Jakarta.

Teguh W, dkk, 2009, Pemanfaatan Limbah Industri Pertanian Untuk Energi Biogas, Balai Besar Pengembangan Mekanisasi Pertanian Badan Litbang Pertanian, Departemen Pertanian. Jakarta. 